\title{
The Value-Added Tax (VAT): Effects on Saudi Economy in The Light of The
} Saudi Vision 2030

\section{Ghadeer Amer Albishi, Basma Alghamdi, Lama AlSubaie, Modhi Almohareb, Hadeel Al-Hamoudi, Haifaa ALakeel, Muneerah Alshabanah}

College of Applied Studies and Community Service, Imam Abdurrahman Bin Faisal University, Dammam, Saudi Arabia.

\begin{abstract}
The aim of this study is to know the impact of Value-added Tax imposition on Saudi economy in light of the Saudi Vision 2030, we assumed that the Value-added Tax leads to an increase in general revenues, and it affects the purchasing power, we also assumed that the provision of subsidies lowers the tax burden. This study follows the descriptive methodology in the literature review and the analytical-inductive methodology in collecting data to examine the assumptions by using a questionnaire. This research generally discussed taxes by reviewing its definitions, characteristics, and objectives, it also mentioned the technical regulations of taxation and analyzed the questionnaire results and estimated the Value-added tax revenues contribution in general revenues. The main conclusions were that the Value-added tax imposition leads to an increase in prices which in turn decreases the purchasing power, also the revenues from the Value-added Tax contributed in increasing general revenues, and the most important recommendations were to establish rules on commercial institutions to prevent prices manipulation after the tax is implemented. In addition, this research recommended directing Value-added tax revenues for infrastructure spending and improving government services.
\end{abstract}

Keywords : Value-Added Tax (VAT), Saudi Vision 2030, Fiscal Balance and Investment.

\section{INTRODUCTION}

The countries of the Gulf Cooperation Council (GCC) currently face a wave of economic fluctuations and financial crises, as these fluctuations and crises led to the deficit in the budgets of these countries and to raise a concern and constant fear about the future of the economy. Subsequently, GCC countries began to search for sources that would revive and increase governmental resources and thus increase the ability to cope with these fluctuations and overcome crises and work to strengthen those economies [1-10].

As public spending and taxes are the most important tools of fiscal policy whose importance in emerging and developing countries outweighs monetary policy, due to the weakening effect of the latter in these countries. Moreover, fiscal policy, as any economic policy, aims to support income stability and economic growth, get rid of distortions, address problems of inflation and monetary stagnation, and achieve equity in the distribution of resources and efficiency in the distribution of expenditures $[1,3,6,11,12]$.

Taxes are at the top of the fiscal policy tools through which the government can provide the necessary financial revenues to finance its public expenditures, rationalize expenditures, stimulate investment, and increase revenues $[1,5,7]$. 
Moreover, tax revenues, especially indirect ones, constitute an important financial resource and at a rate that exceeds direct taxes significantly, so the Gulf Cooperation Council countries have given Priority is to tax reforms and the development of policies that allow diversification of government revenue sources in order to reduce the impact of revenue on oil prices and markets $[10,13,14]$. Among the most important indirect taxes is the value-added tax, which is a recent tax and the result of the development of tax technologies over the past half-century since its establishment by the French economist Maurice Lauré, and it has been applied in various forms in several countries according to their respective economic requirements. Value-added tax is defined as the difference between the price of selling a good or service allowance and the price of purchasing materials and services involved in its production and marketing [5].

Consequently, the government of the Kingdom of Saudi Arabia set a future vision for the Saudi economy in the year 2030 and among the programs of this vision is the program of achieving financial balance in the year 2020 which is among Its provisions include increasing non-oil revenues to enhance government revenues through financial reforms $[3,15,16]$, including imposing a value-added tax and selective tax as one of the safe and sustainable sources for maintaining national income and increasing government revenue.

\section{The Concept of Value-Added Tax (VAT)}

Value-Added Tax is considered an indirect tax, and it is defined as a governmental tax imposed on the stages of production of goods or services, paid by companies that trade the commodity during its conversion from raw material to a manufactured material, and the value of the tax is determined by the value that the company adds to the cost of the raw materials or services $[1,5]$. So, the value-added tax is imposed at every stage of production and the movement of goods through the product, the wholesaler, the retailer, and the consumer who ultimately bears the burden. Thus, value-added tax can also define as consumption tax and borne by the end consumer or the last beneficiary of the service.

\section{The Effect of Value-Added Tax on Consumption, Savings, and Investment}

The value-added tax leads to a decrease in consumption due to the high prices of the goods on which the tax is imposed, which causes the person to balance between necessities and luxuries by choosing between consumption and saving, so we find that the value-added tax helps to reduce unreasonable consumer spending [6]. It also promotes the idea of savings and future consumption spending more than the idea of current consumption spending because that includes obtaining a return as a result of exploiting that part of the income saved. The effect of value-added tax on consumption depends on several factors, including:

The extent of the flexibility of demand for the commodity: Flexible commodities whose consumption is affected by the imposition of the value-added tax significantly compared to inflexible commodities, the demand for inflexible commodities is often the same before and after the imposition of the value-added tax.

- The extent of flexibility of the demand by the community classes to which the tax falls: the rich do not have less consumption as a result of imposing value-added tax because they pay it from their savings, while the poor reduce their consumption capacity, and thus we find that the size of the gross income is inversely proportional to the effect of the value-added tax on consumption. 
Hence, it can be said that the value-added tax plays an important role in the distribution of income between consumption and savings, as it works to reduce consumer spending and thus increase savings and direct these savings to investment and then advance the industry and encourage the production and investment.

\section{The Effect of Value-Added Tax on Prices}

The imposition of the value-added tax on the circulation and consumption of goods or on the profits of importers, producers, and traders will lead to higher prices, especially if they do not depend on transferring their burden to the consumer $[5,6]$. Where the imposition of value-added tax increases the cost and then demands an increase in salaries and wages, the emergence of tax evasion and the selling outside the bill in order to obtain lower prices and this increases inflation.

\section{The Effect of The Value-Added Tax on Income Distribution}

The imposition of value-added tax adversely affects the people with small incomes more than those with high incomes, it is imposed on the classes of society and this will lead to misallocation of income and wealth [3, 17]. So, VAT leads to:

- Reduce irrational consumption.

- Adjust consumption and then improve the economy in the country.

- Increase resources, which helps to narrow the budget deficit and reduce government borrowing, which leads to a decrease in the interest rate and thus stimulates investment.

- Increasing economic efficiency.

\section{The Fiscal Balance Vision Realization Program}

This program includes the supervision and foresight of fiscal performance with the aim to maximize oil and non-oil government revenues in conjunction with improving government spending efficiency and managing risks associated with these processes.

At the beginning of 2016, the Kingdom introduced the Vision 2030, which defined the features of the fundamental change of the economic and social situation. Later on, the agreed national transformation plan was published by government ministries and other sectors for a period up to 2020. Balancing the budget is one of the goals set out in the vision. The program for achieving financial balance is one of the basic programs to achieve the vision, as the program includes strengthening financial management, restructuring the financial situation of the Kingdom and introducing various mechanisms to review revenues, expenditures, various projects, and the mechanism of its approval [1].

During 2015, non-oil revenues were increased by about $30 \%$ and by about $20 \%$ in 2016, and the program aims to continue this field and accelerate it during the coming years through new procedures in multiple sectors and work to improve government performance and ensure the sustainability of financial balance [18].

In addition, this program contributes to improving the basic social and economic impacts that the Vision 2030 aims to achieve. When talking about strengthening non-oil revenues in the financial balance program, the government plans to increase non-oil revenues from 199 in 2016 to 321 in 2020, this increase in non-oil revenues will have direct repercussions on the non-oil private sector in the Kingdom. At the same time, the government may work to improve spending efficiency as well as transparency in the distribution of financial allocations to improve the level of public sector fulfillment of its responsibilities [19]. The financial balance program also included initiatives to increase 
revenues, the most important of which are: indirect taxes, taxes on foreigners, value-added tax, and fees for luxury goods, which was applied during the period 2017-2020.

\section{LITERATURE REVIEW}

Al-Bustami [20] has conducted a comparative study that has revealed the basic features of both the valueadded tax system applied in Palestine and the sales tax law applied in Jordan. The value-added tax system applied in Palestine has been compared to the Jordanian sales tax system in several aspects where the focus is on the source of legislation and the basis for enforcing this Law and registration procedures and how to fill in the monthly returns for this type of tax .As well as, these taxes were compared in terms of the extent of their contribution to public revenue and local revenue, especially the extent of their contribution to tax revenue and thus the extent of their contribution to financing the budget by studying the years 1995-2005 for each of the valueadded tax and sales tax and the analysis of the contribution ratios between them. The importance of the value-added tax in financing revenues in the budget was one of the most important findings of the researcher.

Ben Snoussi et al [21] conducted a study on taxes and their effects on economic development, they clarified the important role that the tax plays in achieving the public benefit and its direct impact on the public revenues of the state and seeks to prove that the tax is an important financial resource in financing the state treasury and that it has great importance in developing the economy and directing activities and providing an appropriate climate that helps in achieving the development process economic. The researchers started with an introductory presentation of the tax and the most important related concepts. Additionally, there is another part has been devoted to presenting the role of tax in economic development in its most important aspects and concluded with an applied case in Bouira province. This study concluded that:

- Taxation is one of the main pillars of the financial system; As it plays a major role in the economic development process as it is an important tool for influencing economic activity and financing various projects and programs.

Economic development primarily targets the individual and requires a change in the production structure.

Taxes can play a major role in reviving the national economy and achieving development requirements under the condition that adequate capabilities and a tight tax system are available.

This study of Mayaleh [22] aimed at identifying the nature of the tax system's relationship with economic, social and political systems. The importance of the tax system in achieving social justice, and the extent to which it is affected by the economic and political system. Each country seeks to achieve its economic and social goals through a set of taxes to form its tax system. One of the social goals is to redistribute wealth and reduce some undesirable purchasing practices. As for economic goals, it plays a big role in encouraging investment. Furthermore, taxes are considered a means of encouraging economic activity in the event of inflation and deflation, since the tax system that is suitable for achieving certain goals in a particular society may not be suitable for achieving these goals in another society because there are differences between societies. To achieve the desired goals of the study, it was relied upon to review the literature of tax and public financial systems as a theoretical framework. The results of this study can be summarized as follows: 
- There is no perfect integrated tax system that is fit for every time and place, but there are basic principles and standards that can be guided by, such as fairness, effectiveness, and applicability

- The political situation greatly affects the financial situation

- The correlation of tax policy with spending policy

\section{METHODOLOGY}

\section{- Study sample description}

The questionnaire was distributed to a sample of financial and economic experts and some who are interested in this field and accordingly the sample was chosen Intentionally to obtain highly accurate data that contributes to the validity of the research hypotheses, and 102 responses were obtained, including 84 economists and 18 non-economists.

\section{- Data collection and analysis}

An inductive analytical approach was followed during data collection, to analyze and explain the impact of the imposition of value-added tax on the Saudi economy under the vision of 2030. The questionnaire was taken as an instrument to validate the hypotheses of the study and the questionnaire data was collected and analyzed by Excel.

\section{RESULTS AND DISCUSSION}

The First Dimension: general information about the members of the sample is presented in figures 1,2 and 3.

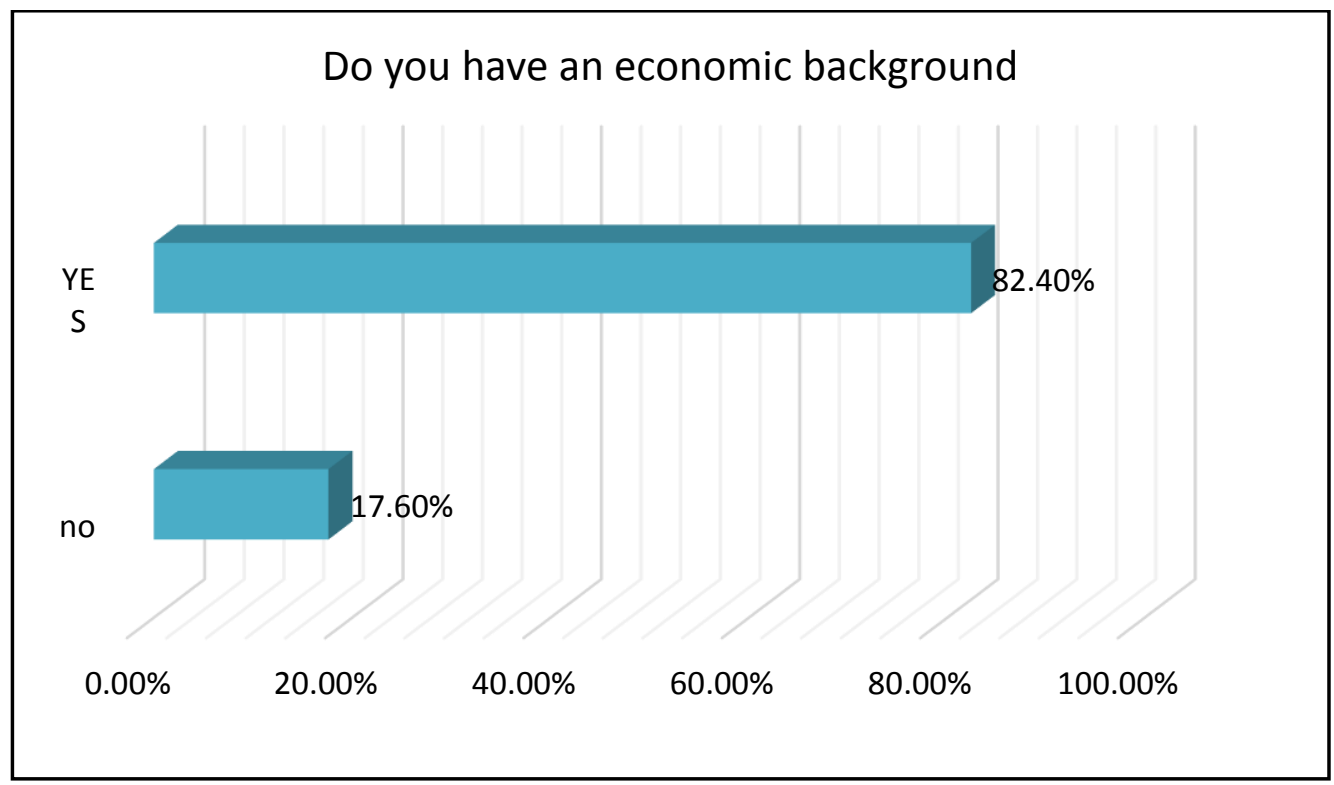

Figure (1): The percentages of those with an economic background. 


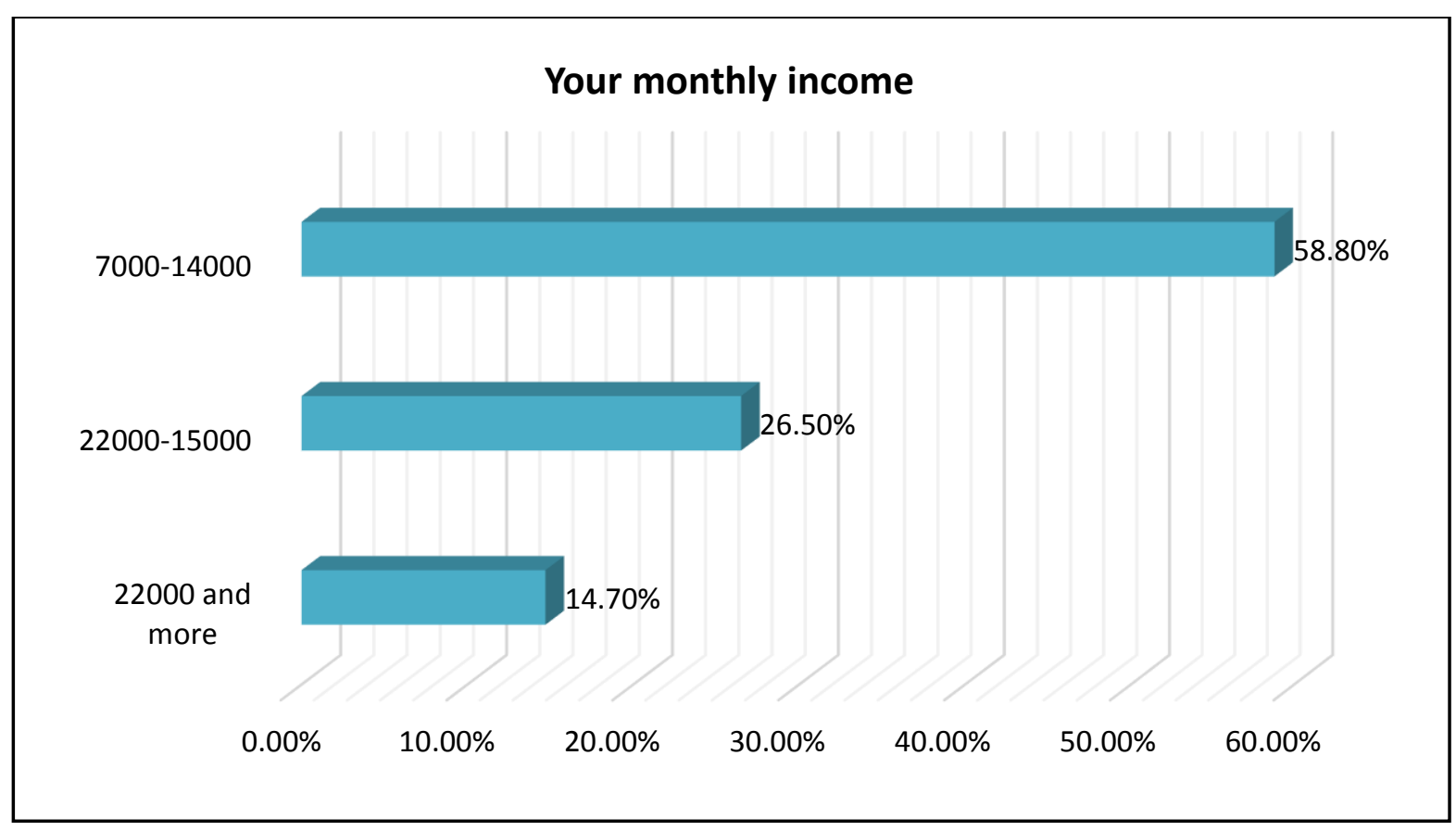

Figure (2): The monthly income of the respondents.

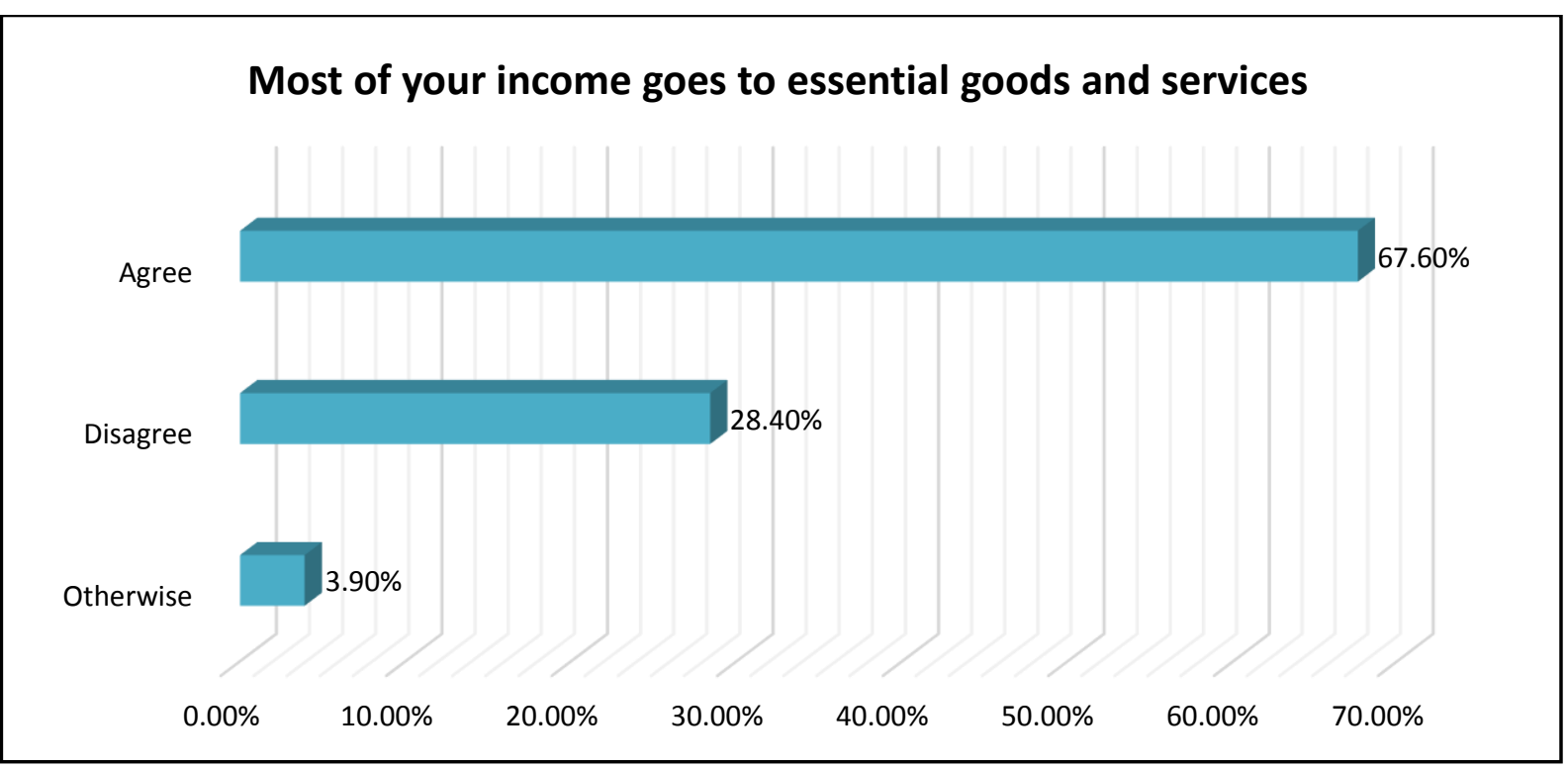

Figure (3): The type of goods and services consumed.

From the previous figures 1, 2 and 3, it becomes clear that most of the respondents are those who have an economic background and their percentage constituted $82.4 \%$, while the percentage of those who do not have an economic background is $17.6 \%$. Also, the majority of their income ranged between 7000 to 14000 and then comes from whose income ranges between 15000 to 22000, whereas $67.6 \%$ of the income goes to the necessary goods and services, while the $3.9 \%$ is the one who answered otherwise and goes to the rent and loan installments, and the researchers noted that those who entered 22000 or more, directed their entry towards the unnecessary goods And investment. 
The Second Dimension: The second dimension financial and tax awareness the responses are involves 4 questions that present information about presented in figures 4,5,6 and 7 .

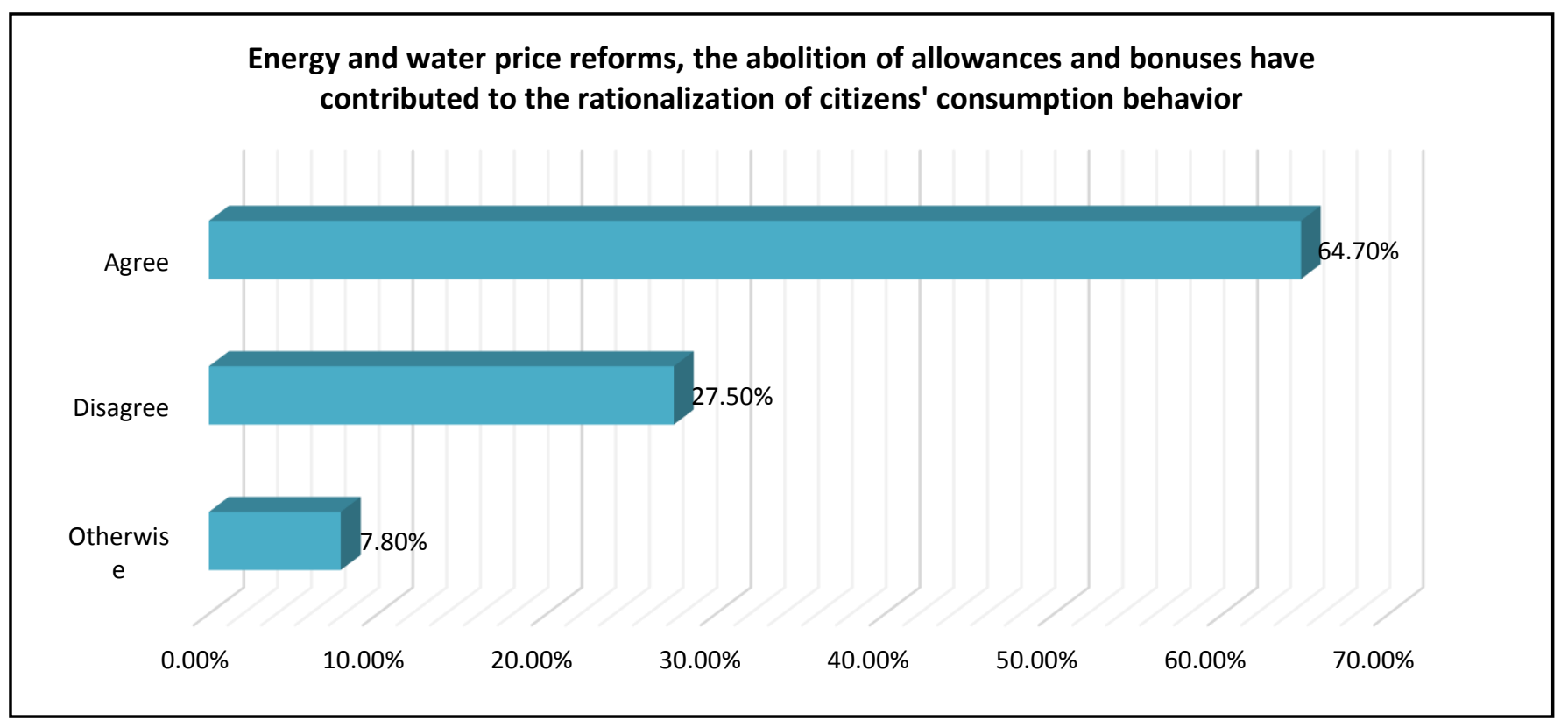

Figure (4): The contribution of reforms in rationalizing consumer behavior.

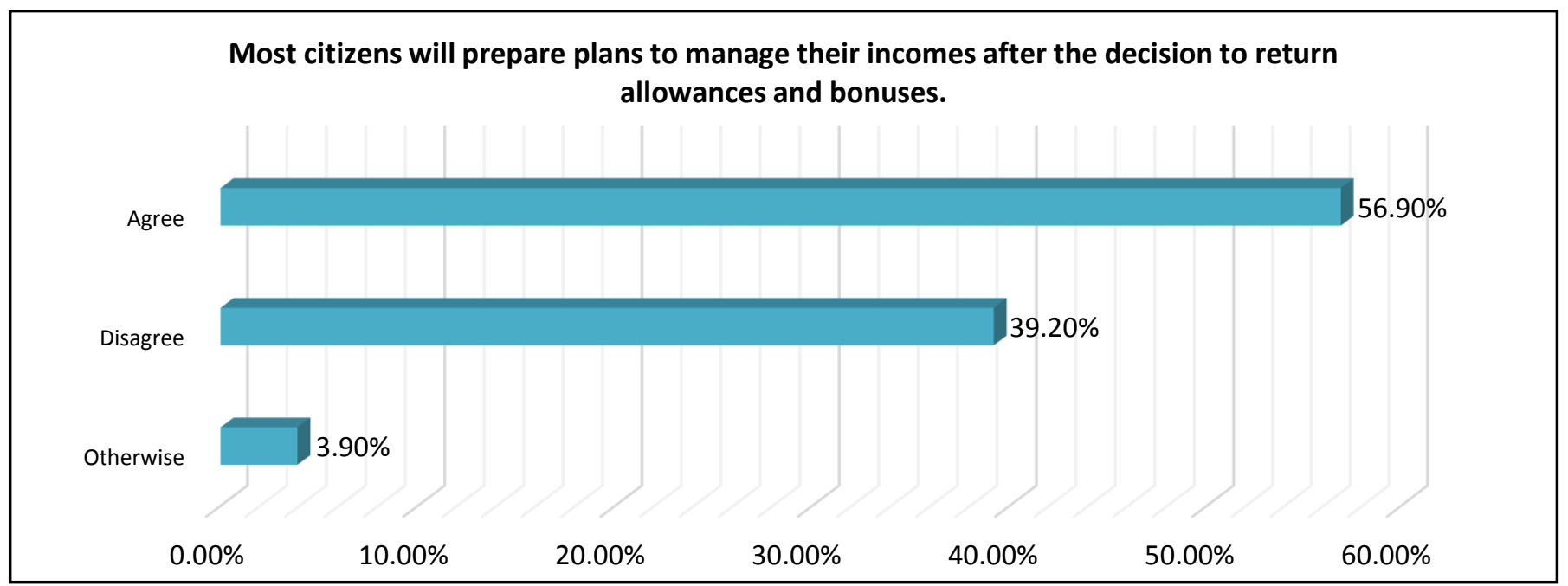

Figure (5): The attitude towards income management.

From figures 4 and 5, the respondents think that the removal of subsidies on energy and water and canceling the allowances, will contribute to rationalizing consumer behavior and increase awareness among the citizen as he begins to distribute his income in a correct manner that contributes to making him a productive citizen more than being a consumer, so a survey was made about a contribution of energy and water price reforms, the abolition of allowances and bonuses in rationalizing consumer behavior, and this was approved by $64.7 \%$ of the respondents, and after the decision to return the allowances they were surveyed about their orientation to prepare plans to manage their incomes, where approval of that accounted for $56.9 \%$ of the respondents. And the answer "No" accounted for 
$39.2 \%$, also $9 \%$ answered otherwise and their answers were that they would search for additional work.

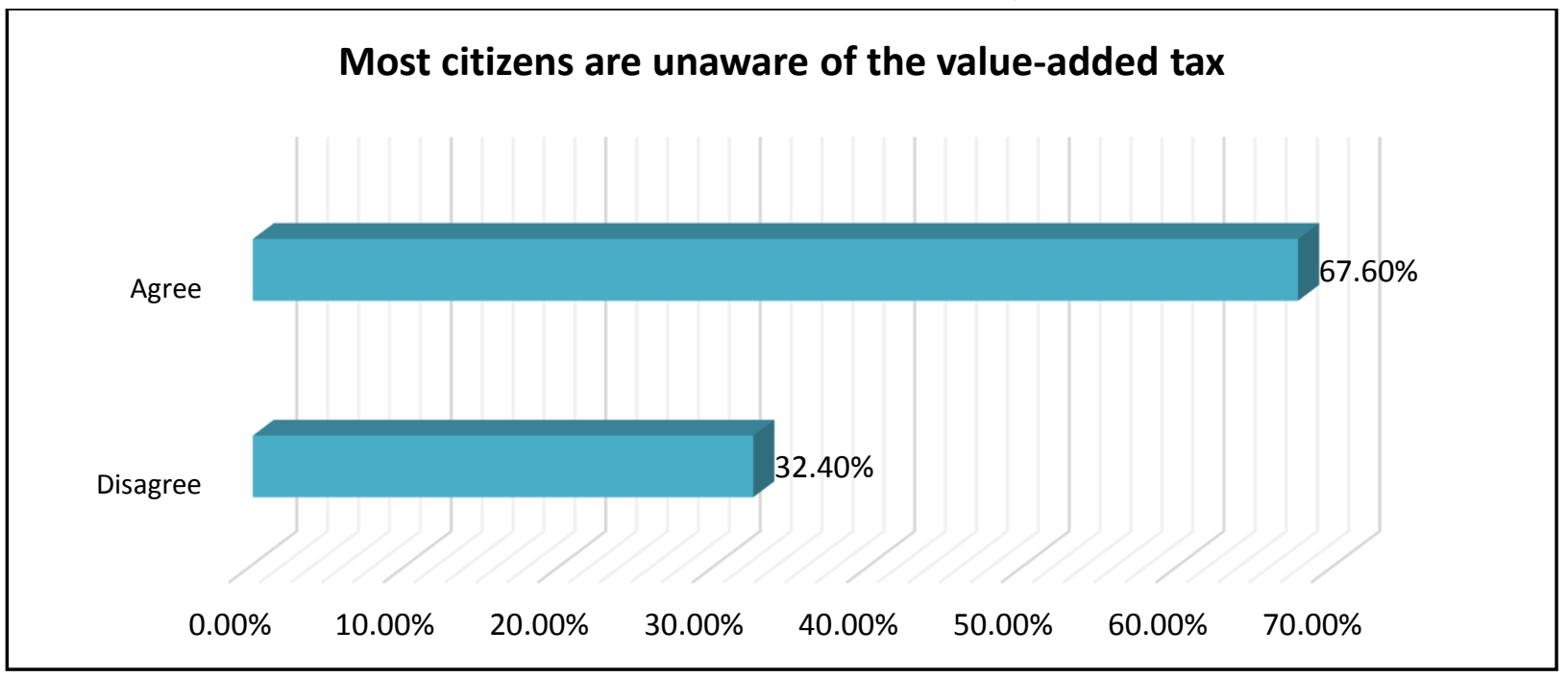

Figure (6): the citizen's awareness of value-added tax.

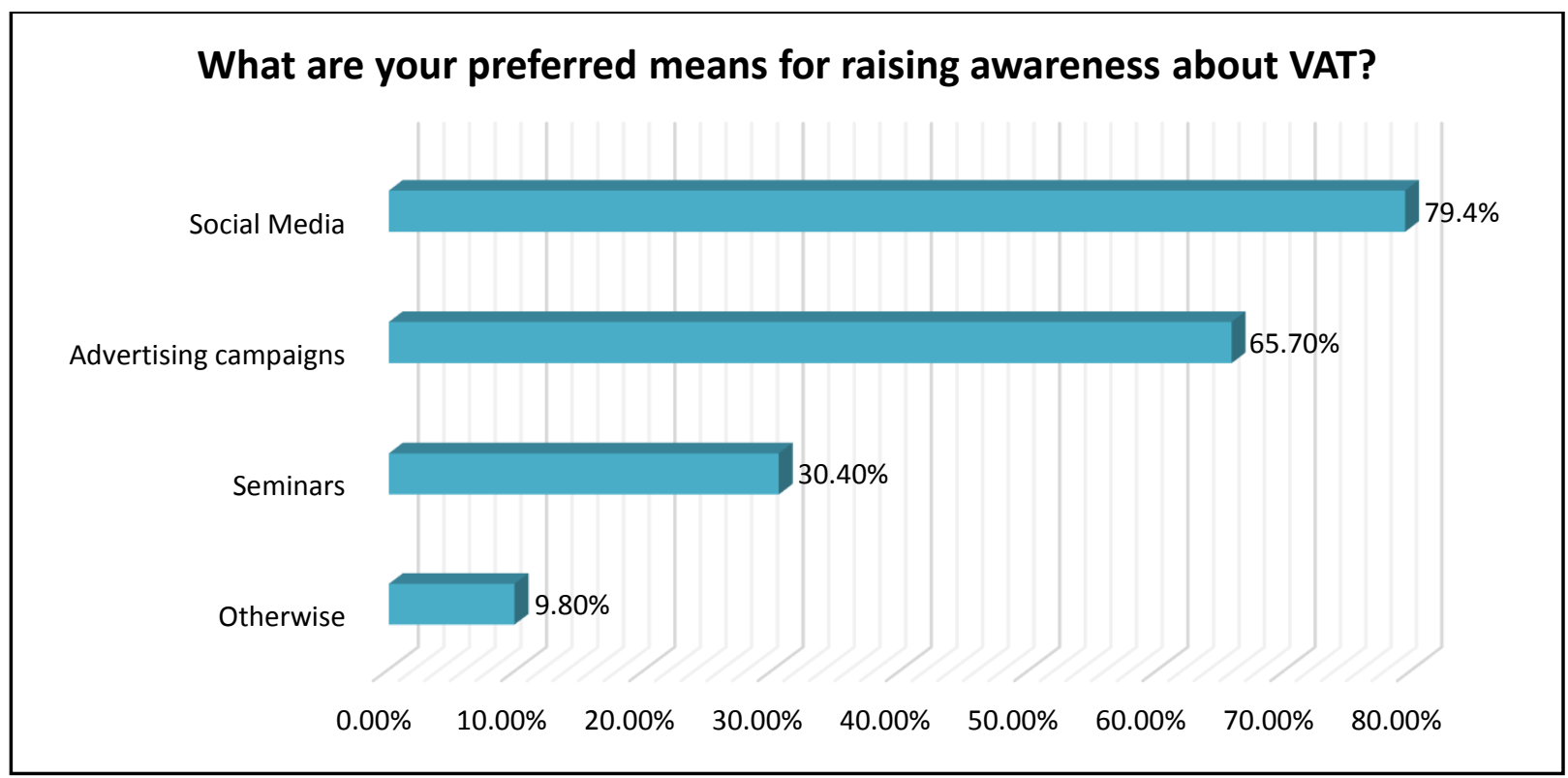

Figure (7): the preferred means for spreading awarenes.

From figures 6 and 7, the percentage of $67.6 \%$ of the respondents believes that the majority of citizens are unaware of the value-added tax, and the majority of the sample members preferred to spread awareness about value-added tax through social networking sites at $79.4 \%$, followed by advertising campaigns at a rate of $65.7 \%$.
The Third Dimension: The questionnaire involved 6 questions about the impact of value-added tax on the Saudi economy, the responses are illustrated in figures 8 to 13 . 


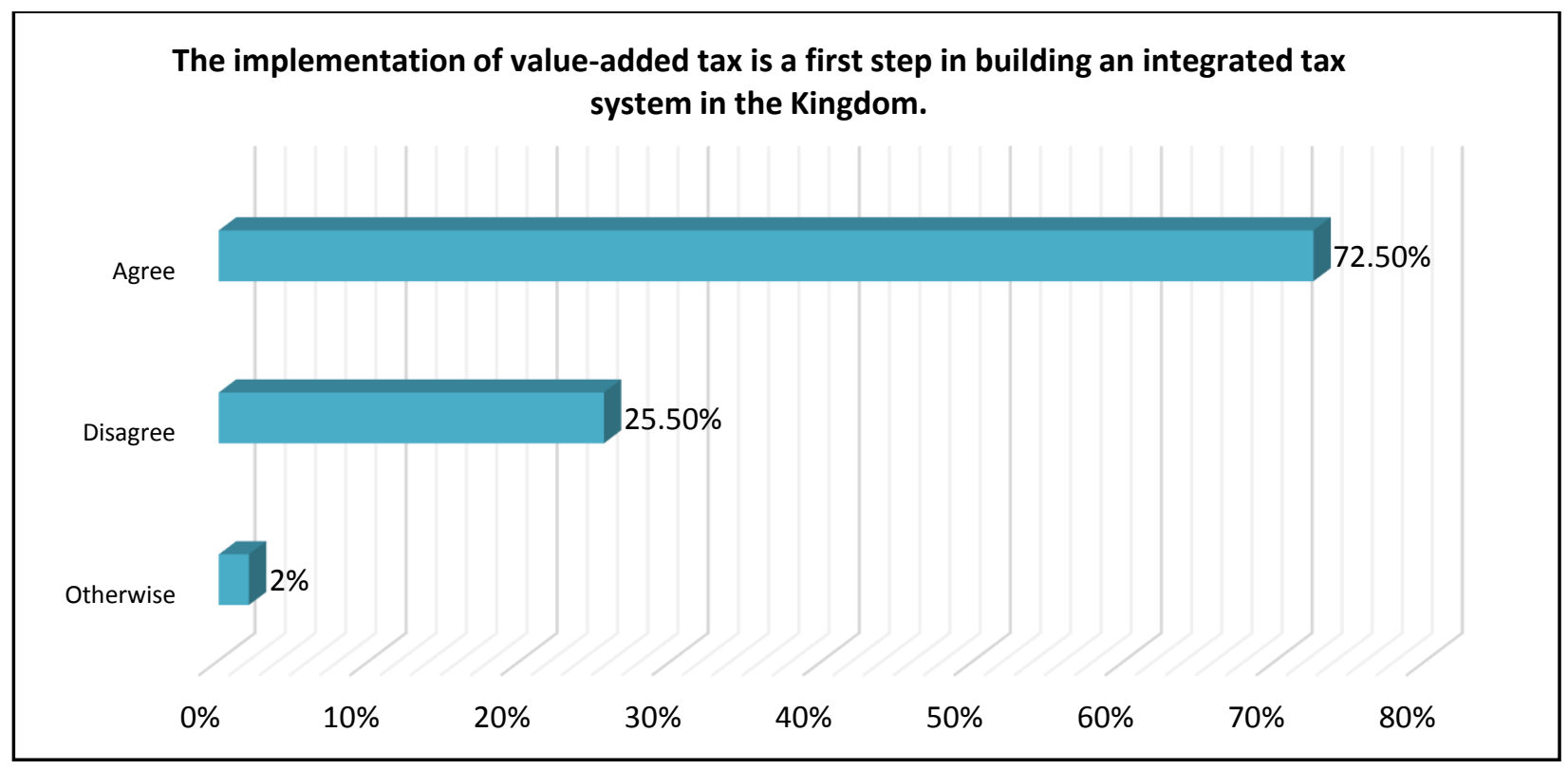

Figure (8): Explains the role of value-added tax in building a tax system.

The Kingdom of Saudi Arabia does not have a tax system in the true concept of the tax system, so one of the paragraphs was devoted to knowing the role of value-added tax in building an integrated tax system, and from figure 8 , the approval rate accounted for $72.5 \%$ of the respondents.

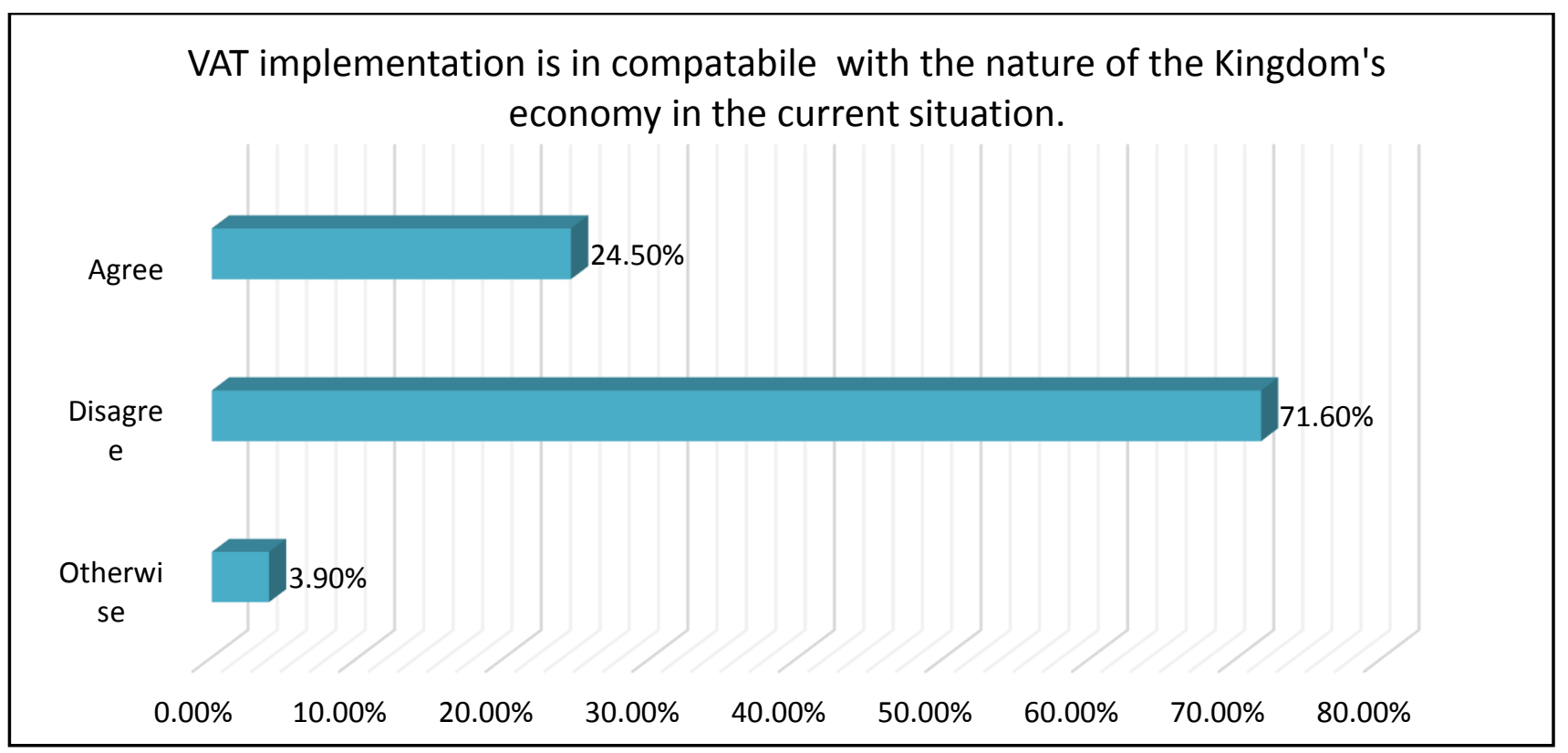

Figure (9): The compatibility of the implementation of VAT with the current state of the economy. 


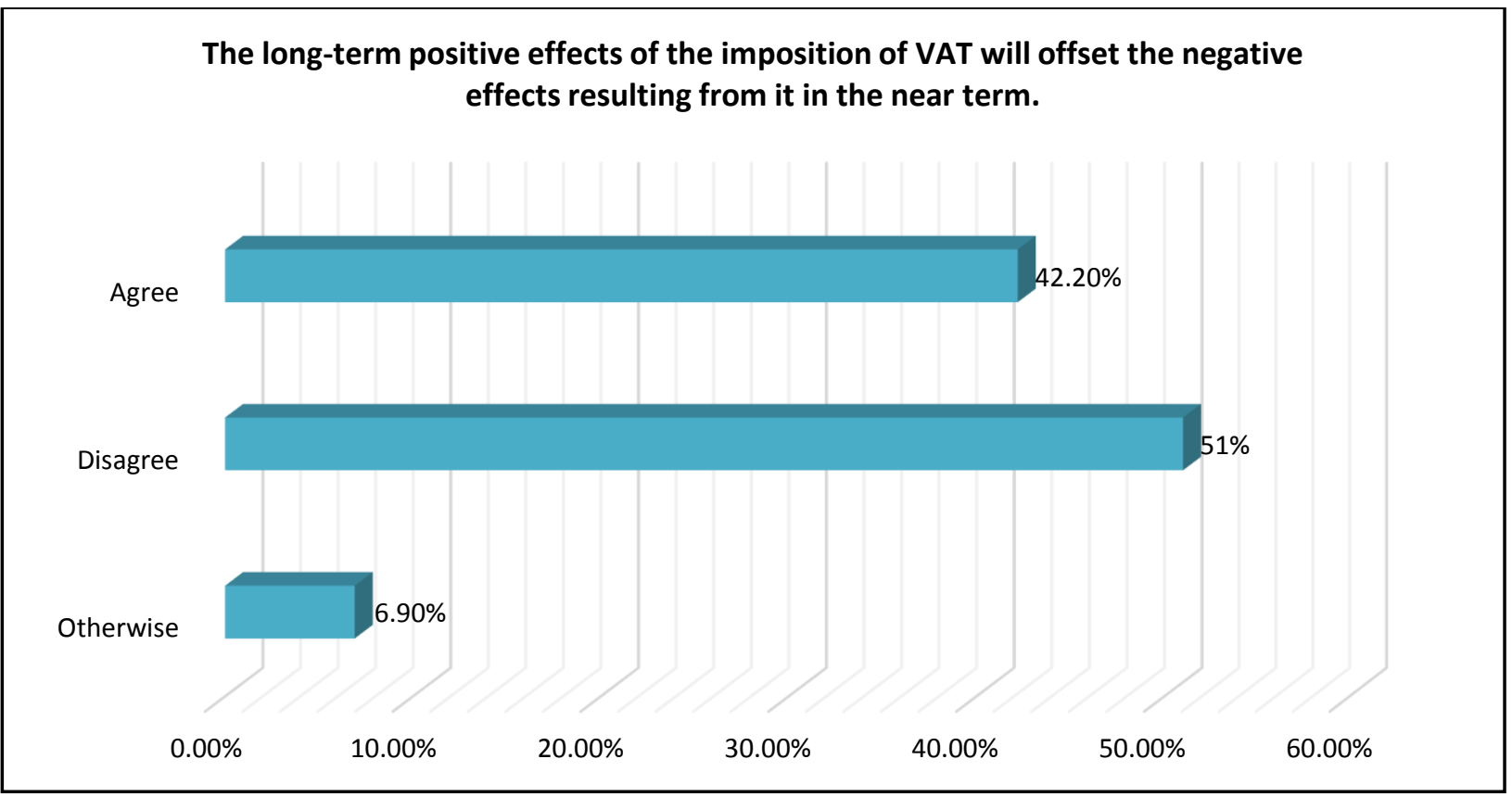

Figure (10): The future effects of value-added tax.

The implementation of the value-added tax must be in line with the current state of the economy in order to achieve better results and to avoid problems, and we have mentioned in the second paragraph in this axis that the application of value-added tax is in line with the nature of the economy in the current situation, and $71.6 \%$ of respondents rejected this. In addition, $51 \%$ of respondents believe that the positive long-term effects of imposing VAT will not compensate for the negative effects resulting from it in the near term. It is believed that the decision to return allowances and bonuses will contribute to the recovery of domestic demand.

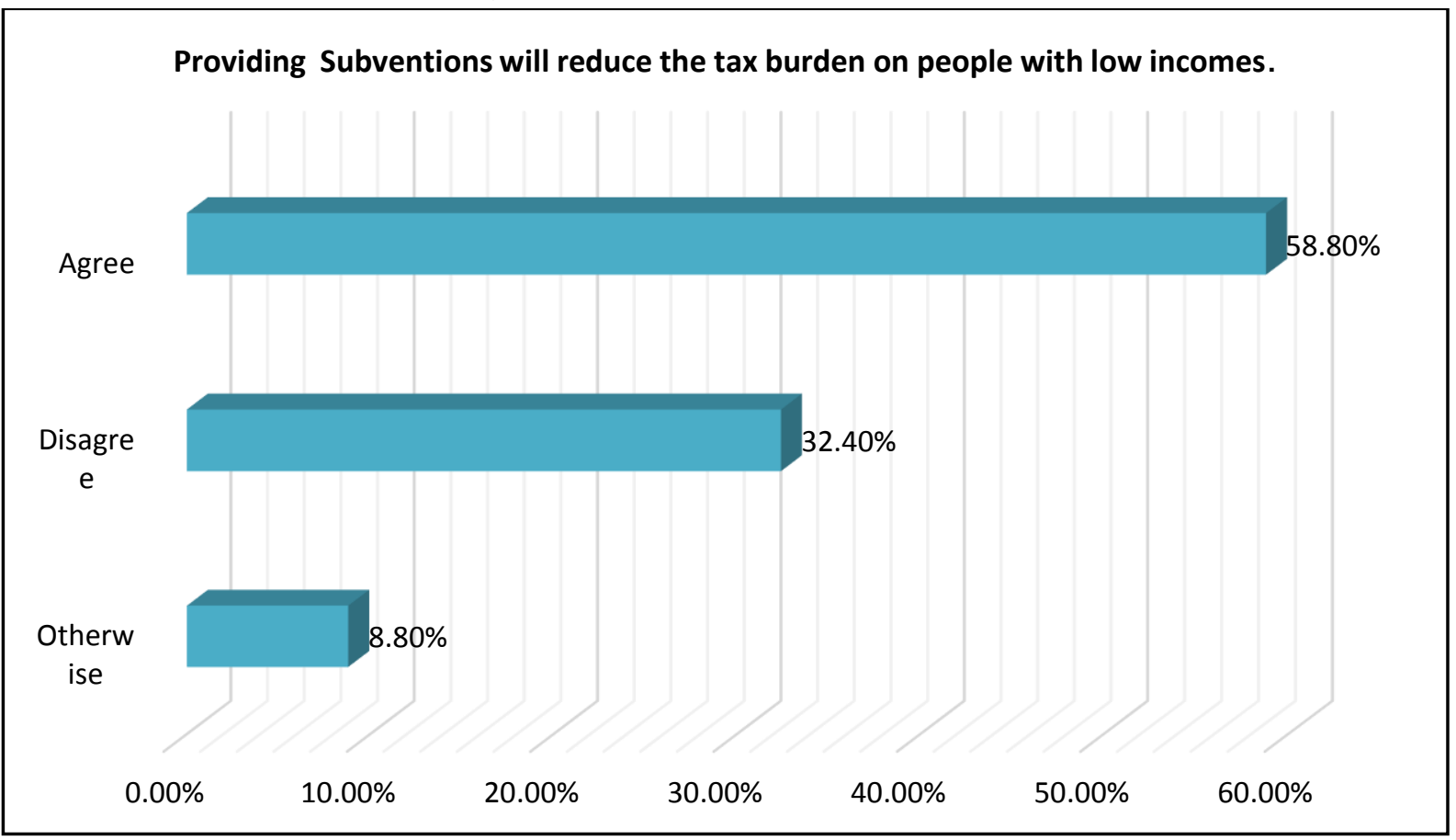

Figure (11): The contribution of the subventions in reducing the tax burden. 
From figure 11 above, 58.8\% of respondents believe that providing benefits reduces the tax burden on people with low incomes, and this supports one of the research hypotheses, which is that providing benefits reduces the tax burden on people with low incomes.

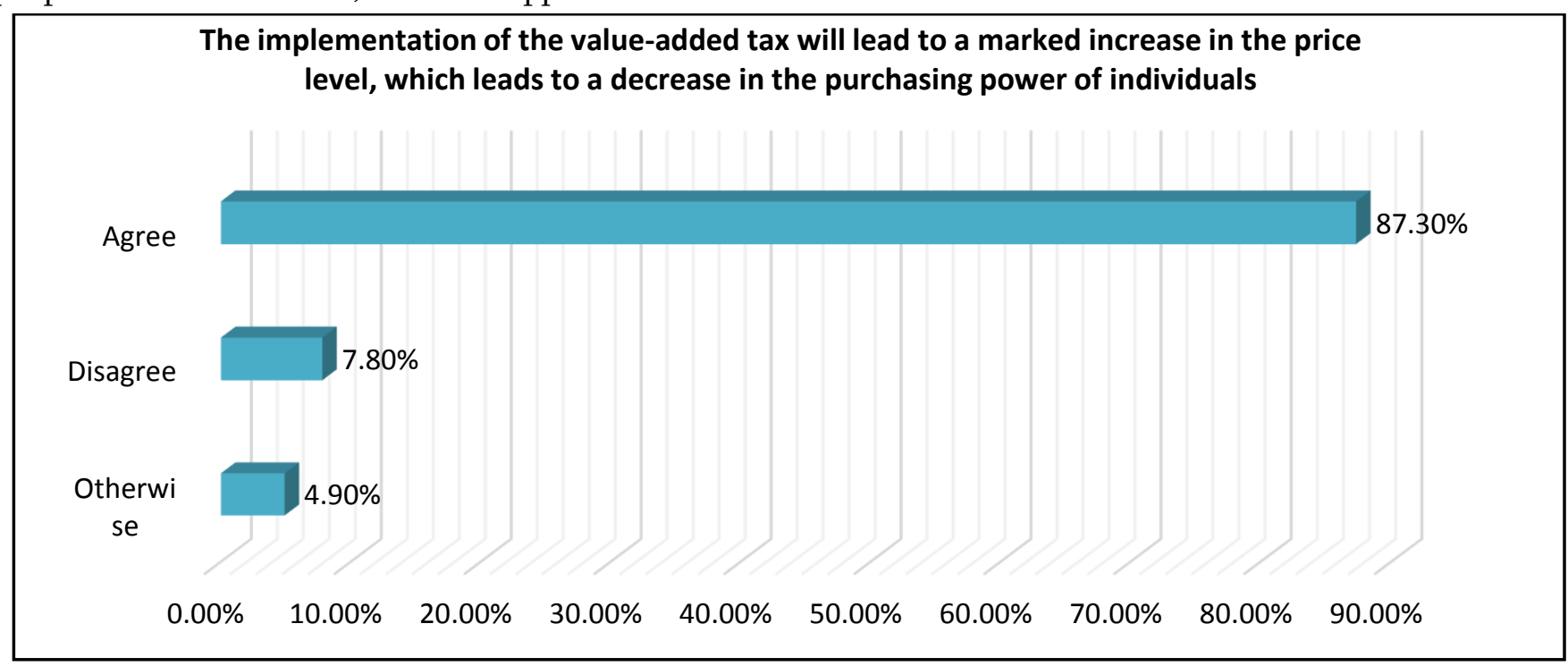

Figure (12): The influence of the individual's purchasing power.

The research hypotheses stated that the imposition of the value-added tax affects the purchasing power of the individual, as it is known that the imposition of the value-added tax leads to a noticeable increase in the price level, which in turn leads to a decrease in the purchasing power of individuals, and what supports this is that $87.3 \%$ of respondents Economists and non-economists believe that it will lead to a high level of prices that reduces the purchasing power of the individuals.

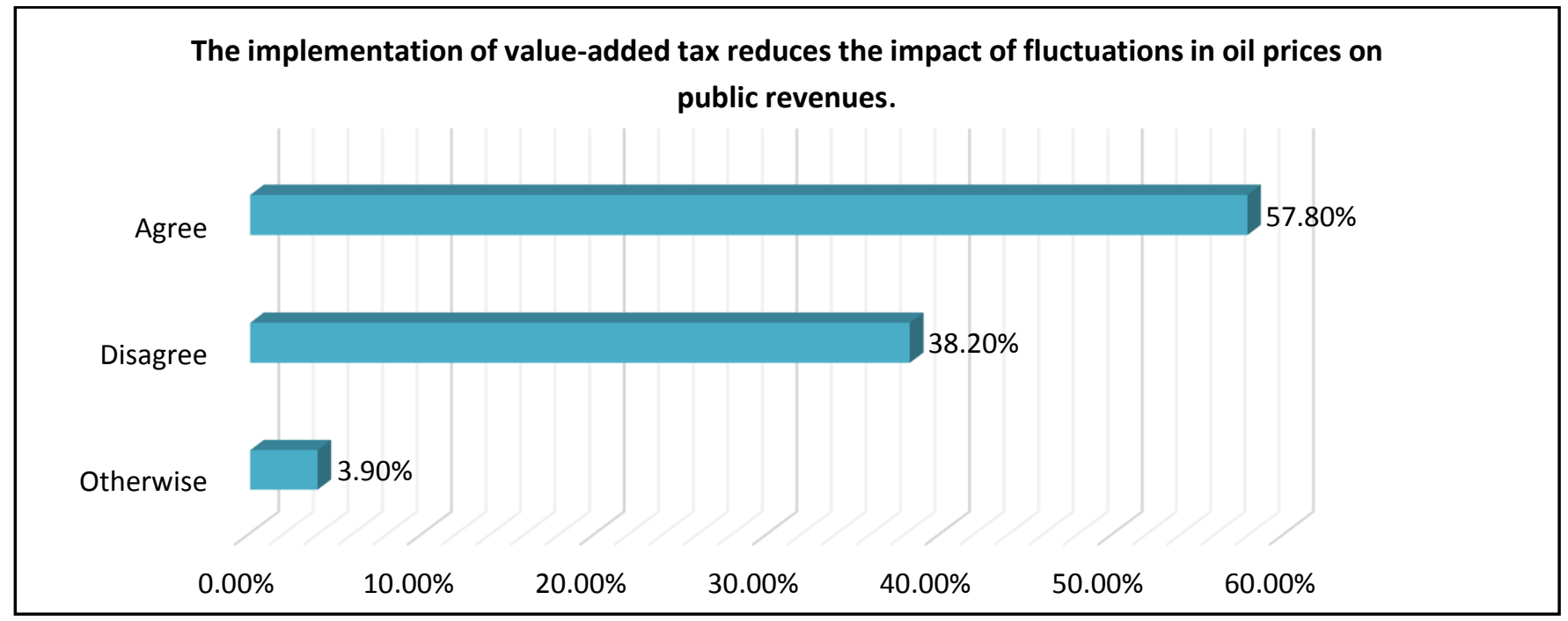

Figure (13): The tax contribution in the general revenues.

From figure 13 above, $57.8 \%$ of respondents believe that the application of the tax reduces the impact of fluctuations in oil prices on public revenues, while the rate of $3.9 \%$ answered otherwise and one of the most prominent answers is that the application of value-added tax is one of the factors.

The first question: "From your point of view, what are the effects of the application of the value-added tax on the economy of the Kingdom of Saudi Arabia?" 
When a question was asked about the effects that respondents expect to occur in the Saudi economy due to the application of value-added tax, there were multiple views of the effects that could occur, as the proportion of those who believe that the application of value-added tax will lead to an increase in the level of prices of goods and services, and thus a decrease in purchasing power among individuals, it constituted approximately (29.41\%), and this supports the research hypothesis, as it constituted (23.54\%) of those who expected revenue from the value-added tax to increase the volume of government revenue, and some added that revenue from the value-added tax will contribute to increasing the quality of government services and infrastructure development. The number of respondents stated that the imposition of the value-added tax will create additional burdens on the individual's in addition to the presence of other burdens as a result of price reforms and their rate was $(12.74 \%)$, and others have expected that the imposition of the tax will contribute to the rationalization of consumer behavior and orientation of individuals savings accounted for (13.72\%), and researchers believe that this leads to increased financial awareness among members of Saudi society.

Some of those who constituted $3.92 \%$ in identifying the directly affected sectors came from the decrease in local demand, as one of them mentioned the decrease in local demand, which will negatively affect the retail sector. Another mentioned that low domestic demand will lead to the closure of institutions and small companies based on local spending, and researchers believe that this can happen in institutions and companies that are actually weak and that the closure of these institutions and companies contributes in the long run to building a market based on strong competition where you are efficient and highly capable companies that can withstand economic instability.
Percentage of $16.66 \%$ of the negative expectations for the imposition of the value-added tax, as the most prominent negative effects, according to what has been mentioned, are the influence of the social class structure in society and the decrease in the size of the middle class. The researchers believe that providing subsidies and support, and making tax exemptions on the necessary commodities will contribute to reducing the negative impact.

The second question: "From your point of view, what are the challenges that will face value-added tax in the Kingdom of Saudi Arabia?"

When a question was asked about the challenges for the value-added tax in the Kingdom of Saudi Arabia, the responses varied, so the society's rejection and lack of tax awareness constituted $32,4 \%$ of the respondents, which explains the low tax awareness in Saudi society, and the reasons for rejection differed among them. It had a religious or political reason, and this is due, from the researchers' point of view, that taxes are a new concept for Saudi society, and 15.69\% of the respondents agreed that the purchasing power will decrease as a result of the taxation and this supports the research hypothesis in addition that $8,82 \%$ of the respondents thought that prices would go up. These challenges constitute a burden on families with low incomes and raise the cost of living, which causes a reduction in the total demand for goods and services, and challenges were formed in the opinion of $21,57 \%$ of the respondents in challenges related to the systems, their efficiency and readiness. Also, 6,86\% of the challenges are various economic challenges, such as inflation, and low competitiveness within the local market, in contrast to $14.7 \%$ of the respondents had no idea about the possible challenges, and there are other challenges from the researchers point of view, such as the recent application of this type of tax in the Kingdom of Saudi Arabia, and the lack of advertising About taxable goods and exempt from it. 


\section{CONCLUSION}

This study examined the impact of Value-added Tax imposition on Saudi economy in light of the Saudi Vision 2030, it concluded that the Value-added Tax leads to an increase in general revenues, and it affects the purchasing power, the provision of subsidies lowers the tax burden, this study followed the descriptive methodology in the literature review and the analytical-inductive methodology in collecting data to examine the assumptions by using a questionnaire. The questionnaire results were analyzed, the main conclusions were that the Valueadded tax imposition leads to an increase in prices which in turn decreases the purchasing power, it also the revenues from the Value-added Tax contributed in increasing general revenues. Moreover, the most important recommendations were to establish rules on commercial institutions to prevent prices manipulation after the tax is implemented. Additionally, it is recommended directing Valueadded tax revenues for infrastructure spending and improving government services.

\section{REFERENCES}

[1]. Moshashai D, Leber A M and Savage J D. Saudi Arabia plans for its economic future: Vision 2030, the National Transformation Plan and Saudi fiscal reform. British Journal of Middle Eastern Studies, 2018: 1-21.

[2]. Habibi N. Implementing Saudi Arabia's Vision 2030: An Interim Balance Sheet. Middle East Brief, 2019, 127: 1-9.

[3]. Esmail H. Economic growth of Saudi Arabia between present and future according to 2030 vision. Asian Social Science, 2018, 14(12): 192.

[4]. Faudot A. Saudi Arabia and the rentier regime trap: A critical assessment of the plan Vision 2030. Resources Policy, 2019, 62: 94-101.
[5]. al-Tamimi N. Saudi Vision 2030 and the Consequences Of the Gulf Crisis. 2017.

[6]. Alkhodre A, Jan S, Khusro S, Ali T, Alsaawy Y and Yasar M. A Blockchain-based Value Added Tax (VAT) System: Saudi Arabia as a Use-Case. 2019.

[7]. Naseem $S$ and Khan W. VAT a New Move Directing KSA's Development. Res J Econ 2: 2. of, 2018, 2: 2.

[8]. Khashan H. Saudi Arabia's Flawed" Vision 2030". Middle East Quarterly, 2017.

[9]. Bouoiyour J and Selmi R. The gruesome murder of Jamal Khashoggi: Saudi Arabia's new economy dream at risk? arXiv preprint arXiv:1812.11336, 2018.

[10]. Bah M M and Saari M Y. Quantifying the impacts of energy price reform on living expenses in Saudi Arabia. Energy Policy, 2020, 139: 111352.

[11]. Violi S. Saudi Arabia Faced with Modernity: from the Demographic Transition to'Vision 2030'. Università Ca'Foscari Venezia, 2017.

[12]. Ejaz M, Tashfeen R, Younas K and Naeem A. Economic Value Added or Earnings per Share? An Incremental Content Analysis. Empirical Economic Review, 2018, 1(2): 63-90.

[13]. Alharbi A. Economic effects of low oil prices in Saudi Arabia. International Journal of Information Technology: 1-6.

[14]. Khan K, Su C-W and Tao R. Does Oil Prices Cause Financial Liquidity Crunch? Perspective from Geopolitical Risk. Defence and Peace Economics, 2020: 1-13.

[15]. Anser M K, Yousaf Z, Zaman K, Nassani A A, Alotaibi S M, Jambari H, Khan A and Kabbani A. Determination of resource curse hypothesis in mediation of financial development and clean energy sources: Go-for-green resource policies. Resources Policy, 2020, 66: 101640.

[16]. AlOtaibi Z S, Khonkar H I, AlAmoudi A O and Alqahtani S H. Current status and future 
perspectives for localizing the solar photovoltaic industry in the Kingdom of Saudi Arabia. Energy Transitions, 2020: 1-9.

[17]. Alavuotunki K, Haapanen M and Pirttilä J. The consequences of the value-added tax on inequality. 2017.

[18]. Budget Statement Fiscal Year 2020. https://www.mof.gov.sa/en/financialreport/bud get2020/Documents/Bud-Eng2020.pdf. 20-32020.

[19]. Fiscal Balance Program 2020. The Path to Fiscal Sustainability.

https://www.google.com/search?ie=utf-

8\&oe $=$ utf-

$8 \&$ cso $=1 \& \mathrm{q}=$ the + government + plans + to + increase +non-

oil+revenues+from $+199+$ in $+2016+$ to $+321+i n+20$

20. 20-3-2020.

[20]. Al-Bustami Muayad, Value Added Tax Applied in Palestine and Sales Tax Applied in Jordan (Comparative Study), Palestine, College of Graduate Studies at An-Najah National University, 2006

[21]. Ben Snoussi, Laila and Jadid, Masouda, Taxes and their Effects on Economic Development (Case Study at the Tax Inspectorate in Bouira), Algeria, Ministry of Higher Education and Scientific Research, University Center, Colonel Akli Mohand Muhannad Al-Bouira, 2009.

[22]. Mayaleh Muayad, The Relationship of the Tax System with Economic, Social, and Political Systems in Palestine, Nablus, Palestine, AnNajah National University, College of Graduate Studies, 2006.

\section{Cite this article as :}

Ghadeer Amer Albishi, Basma Alghamdi, Lama AlSubaie, Modhi Almohareb, Hadeel Al-Hamoudi, Haifaa ALakeel, Muneerah Alshabanah, "The ValueAdded Tax (VAT): Effects on Saudi Economy in The Light of The Saudi Vision 2030", International Journal of Scientific Research in Science and Technology (IJSRST), Online ISSN : 2395-602X, Print ISSN : 23956011, Volume 7 Issue 2, pp. 201-214, March-April 2020. Available at doi : https://doi.org/10.32628/IJSRST1207229 Journal URL : http://ijsrst.com/IJSRST1207229 